УДК 316.33

$10.17213 / 2075-2067-2021-3-46-51$

\title{
ПОНЯТИЕ СОЦИАЛЬНОЙ АДАПТАЦИИ МАЛООБЕСПЕЧЕННОЙ СЕМЬИ В УСЛОВИЯХ СОЦИАЛЬНЫХ ПРЕОБРАЗОВАНИЙ
}

\author{
(C) 2021 г. Л. С. Николаева, О. В. Загорская
}

Новочеркасский инженерно-мелиоративный институт имени А. К. Кортунова (филиал), Донской государственный аграрный университет, г. Новочеркасск, Россия

Цель исследования. $B$ данной статье анализируются проблемы социальной адаптации малообеспеченной семьи в условиях сочиальных преобразований.

Методология исследования основана на сочиильно-философских и сочиальных идеях и методах, отраженных в творчестве таких ученых, как М.А. Шабанова, Л.В. Корель, Т. И. Заславская, Н. Ф. Наумова, А. И. Кравченко и др.

Результаты исследования. Делается вывод о том, что социиальная адаптация малообеспеченной семьи опирается на развитие, открытость новым преобразованиям, использование предыдущего опыта, ответственное выполнение задач и иелей, способность преодолевать жизненные трудности, креативность, развитие положительных эмоций, уверенность в будущем.

Ключевые слова: семья; сочиальная адаптация семьи; малообеспеченная семья; бедность.

\section{THE CONCEPT OF SOCIAL ADAPTATION OF A LOW-INCOME FAMILY IN THE CONTEXT OF SOCIAL TRANSFORMATIONS}

(C) 2021 L. S. Nikolaeva, O. V. Zagorskaya

Novocherkassk Reclamation Engineering Institute named after A. K. Kortunov (branch), Donskoy State Agrarian University, Novocherkassk, Russia

The purpose of the study. This article analyzes the problems of social adaptation of lowincome families in the context of social transformations.

The research methodology is based on the socio-philosophical and social ideas and methods reflected in the works of such scientists as M. A. Shabanova, L. V. Korel, T. I. Zaslavskaya, N.F. Naumova, A.I. Kravchenko, etc.

The results of the study. It is concluded that the social adaptation of a low-income family is based on development, openness to new transformations, the use of previous experience, responsible performance of tasks and goals, the ability to overcome life difficulties, creativity, the development of positive emotions, confidence in the future.

Key words: family; social adaptation of the family; low-income family; poverty. 
Введение. Процесс адаптации весьма сложный и возможен только при деятельном участии сознания. Человек своей активной жизненной позицией может изменить сам процесс социальной адаптации, а не только его пассивно воспринимать. Необходимо отметить, что процесс адаптации семьи, безусловно, осуществляется в обществе, носит социально-деятельностный характер в коллективах и группах. Кроме того, социальная адаптация семьи зависит от ее общественного положения, социальных связей, среды. Как известно, социальная адаптация не является безоговорочным принятием человеком или группой определенных условий жизни. Малообеспеченная семья (бедная семья) в разных условиях стремится изменить реальность, исходя из определенных ситуаций своего существования, и в соответствии с этим вырабатывает действенный механизм своей активности, что и определяет саму стратегию адаптации.

Социальную адаптацию понимают, опираясь на понятие «социальный процесс», который представляет сочетание множества однонаправленных, часто повторяющихся действий в обществе, основывается на сотрудничестве, конкуренции, конфликтах, столкновении интересов, подчинении, приспособлении, гармонизации отношений в социуме и других регулярно повторяющихся отношений, связей, сохранении определенных границ и обслуживания и проявляется в группах. Социальная адаптация особенно большое значение имеет для малообеспеченной (бедной) семьи в современных социально-экономических реалиях общества.

Основная часть. Проблема социальной адаптации всегда волновала российских исследователей. Они активно развивали структурно-деятельностный подход, делая акцент на том, что адаптация характеризуется в ситуации социально-экономических преобразований как безальтернативное поведение людей в социуме [3]. Для исследования малообеспеченной (бедной) семьи этот подход наиболее актуален. М.А. Шабанова, Л.В. Корель, Т.И. Заславская и др. активно разрабатывали его в своих исследованиях. Так, российский ученый М.А. Шабанова полагает, что социальная адаптация осуществляется в той или иной ситуации, исходя из личностного свободного выбора человека или социальной группы [7]. Сам подход основывается на том, что социальный прогресс возможен только на базе расширения возможностей развития людей в процессе их деятельности. Особенно это важно сегодня для малообеспеченных (малоимущих) семей, чтобы в реальной социальной действительности, в условиях социально-экономических преобразований учитывались и соблюдались некоторые принципы. Во-первых, это добровольность участия малообеспеченной семьи в новых моделях поведения, причем чтобы новые способы общественных действий гармонично вписывались в ее ценностные предпочтения, ориентации, способы действий, позиции, внутренний мир семьи.

Во-вторых, для малообеспеченной семьи важно расширение степени свободы для большего количества людей, чтобы в своих стратегиях поведения они могли реализовывать свои цели жизни, опираясь на те способы социальной адаптации, которые гарантируют их приспособление к новой социально-экономической реальности. Реформирование часто ведет не только к изменению, но и к разрушению макросистемы, ее основополагающих оснований: культурных, экономических, экологических и др. Это, безусловно, затрудняет социальную адаптацию малообеспеченных семей. Также необходимо учитывать, что развитие производительных сил должно расширять свободу действий для современных и будущих поколений.

В-третьих, большое значение имеет реализация жизненно важных целей для малообеспеченной семьи в новой социально-экономической ситуации [7].

М.А. Шабанова подчеркивает, что социальную адаптацию следует изучать в контексте добровольной или вынужденной адаптации. Для малообеспеченной, бедной семьи добровольная адаптация возможна, если только ее существующая система ценностных ориентаций не вступает в непримиримое противоречие со средой и новыми социальными ценностями и отношениями. Вынужденная адаптация осуществляется лишь в том случае, когда социально-экономические перемены, методы их осуществления и направления их развития не противоречат 
ценностям, ориентациям, установкам малообеспеченной семьи [7].

На наш взгляд, в современном российском обществе большинство населения осуществляет вынужденную адаптацию к социально-экономическим переменам. Малообеспеченная, бедная семья сознательно и активно приспосабливается к условиям современного общества. В новой ситуации бедная (малообеспеченная) семья, несмотря на то, что она стремится сохранить свои прежние особенности жизни, ориентируясь на стабилизирующую адаптацию, может изменить параметры своей адаптации в сторону улучшения или ухудшения. Исходя из природы изменения, можно выделить прогрессивную (творческую) или регрессивную (разрушительную) адаптацию. Прогрессивная адаптация характеризуется положительной тенденцией и приобретениями в жизни семьи, регрессивная же адаптация, наоборот, - потерями и отрицательной тенденцией в положении семьи. В первом случае углубляется положительная прогрессивная адаптация, а во втором - регрессивная.

Приспособление к условиям окружающей среды может выступать в функциональной форме как процесс, в котором изменения внешней среды влияют на деятельность семьи, преобразовывая ее существование в социуме; в форме коадаптации, когда происходит приспособление организмов друг к другу; пассивная форма адаптации осуществляется без участия семьи; активная форма адаптации проявляется, когда семья деятельно влияет на среду; активистская (объективная) форма адаптации осуществляется, когда семья воздействует на среду в целях своего приспособления и среда изменяется [6].

Большое значение для изучения социальной адаптации имеет стратегия адаптации, которая понимается как приспособление к организационному, социокультурному, институциональному и деятельностному изменениям поведения [3]. В процессе социального поведения малообеспеченная семья осуществляет спонтанную стратегию адаптации (многовекторную), так как прежние адапционные практики и социокультурные нормы в условиях их изменения оказываются неэффективными.

Существуют разные оценки и критерии эффективности адаптационного процесса.
Но большинство исследователей выделяют объективные (социальное положение) и субъективные (здоровье, самочувствие, субъективные самооценки людей) критерии [4]. Интересна позиция Н. Ф. Наумовой, которая выделила три модели адаптационного поведения: 1) эффективная внешняя адаптация базируется на успешном восприятии изменений в экономике, социуме; 2) эффективная внутренняя социальная адаптация основывается на неприкосновенности всей системы ценностей независимо от внешних влияний; 3) стратегия выживания осуществляется людьми с низким социальным статусом и ресурсами, которые самоидентифицируются с социальными группами в такой же ситуации. В этом случае большое значение имеет индивидуальность людей, их особенности, отношение к переменам, ценности, жизненный опыт. Человек в этом случае играет активную или пассивную роль. Эту проблему исследовали Баззо, Бадура, Росс, Парсонс, Шеффилд и др., объясняя ее как освоение социальных ролей в процессе социальной адаптации [2].

Для социальной адаптации важен непосредственный или сознательный поиск решения проблем в изменившихся условиях экономической и общественной жизни. В этом плане выделяют две большие группы процессов социальной адаптации. К первой непосредственной форме относятся процессы, вызванные объективной потребностью общества изза возникающей угрозы для существования какой-либо сферы или стороны общественной жизни. Для нее характерно подчинение окружающей среде без стремления что-либо изменить в условиях социума. Сознательная форма проявления процессов социальной адаптации выявляется в тенденции свободы человека в использовании новых возможностей, чтобы повернуть их в свою пользу для гармонизации отношений с окружающей средой и найти благоприятные возможности для оптимального сосуществования с обществом. Проблему адаптации человека в условиях социально-экономических, культурных, политических, экологических изменений исследовали Е. М. Авраамова, Е. С. Балабанова, Т.П. Матяш, А.И. Кравченко, А.В. Мотыль, О.Н. Дудченко и другие.

Для социальной адаптации малообеспеченных семей характерна специфика разли- 
чий их в общественной, гражданской жизни, ценностей, социального поведения. Переход к новым социальным стандартам в ситуации потери социального статуса, бедности малообеспеченной семьи диктует необходимость овладения новыми ресурсами адаптации, новыми навыками, приемами технологий социальной адаптации в зависимости от жизненных обстоятельств, принятой системы механизмов реализации приоритетов в законодательном порядке, социальных, экономических и правовых гарантий, социальной работы и в целом от всех институтов общества. Если их потенциал непрозрачен, то требуется социальная защита таких малообеспеченных семей от неблагоприятных обстоятельств для социального обеспечения, реабилитации, трудоустройства, образования, решения педагогических, медицинских и психологических проблем, активизации служб по связям с общественностью и информацией.

Социальную адаптацию малообеспеченных семей необходимо рассматривать в русле активизации их адаптивных действий в целях создания оптимальных условий для конкурентоспособности, профессионального обучения, информированности, осведомленности. Многое здесь зависит от ценностей, интересов, особенностей индивидуальности и социального поведения, ресурсов адаптации, образовательного, профессионального, культурного, информационного и социального капитала, реальной адекватной самооценки, нервно-психологической устойчивости. Выработка стратегии адаптации затрудняется, если ресурсов недостаточно или они на очень на низком уровне.

Т.И. Заславская в зависимости от ресурсов выделяет достижительные, адаптационные, регрессивные и разрушительные модели поведения [1]. Положительные конструктивные модели социальной адаптации основаны на активном целеустремленном использовании ресурсов человеческой деятельности, межличностной сети, самозанятости, развитии, саморазвитии индивидуальности и семьи. Неконструктивные модели социальной адаптации характеризуются пассивностью, защитой, иждивенчеством. Чтобы преодолеть или исключить неконструктивные формы поведения, необходимо овладеть механизмом и технологиями адаптации с це- лью моделирования ситуаций, адекватного реагирования на потребности изменений для активного реагирования в сложных ситуациях изменений. Это необходимо, чтобы найти ресурсы для положительного решения проблем, практической реализации своих целей и преодоления трудностей (низкое материальное положение, бедность, недостаток ресурсов, отсутствие профессиональных навыков и знаний, проблемы психологического характера, здоровье). В современной России существует государственная система льгот, прав, гарантий, меры социальной защиты малообеспеченных семей, действующий механизм социальной защиты людей, попавших в трудную жизненную ситуацию. Для малообеспеченных семей важна социальная помощь, социальное обеспечение, помощь в получении образования, медицинская помощь, обеспечение работой, использование средств и методов коммуникаций, психологопедагогическое обслуживание.

Заключение. Таким образом, эффективная (успешная) конструктивная социальная адаптация малообеспеченной семьи направлена на: 1) развитие, открытость новым преобразованиям, увеличение значимости собственной индивидуальной активности; 2) использование предыдущего опыта и положительного настроя в жизненных ситуациях; 3) постановку и ответственное выполнение поставленных человеком задач, стремление к достижению жизненных целей; 4) обдуманное умение организовать жизнь и способность преодолевать жизненные трудности, используя разные возможности и окружение человека; 5) развитие положительных эмоций, креативность в принятии решений; 6) уверенность в будущем, компетентное управление организацией повседневного бытия и активную деятельность человека в обществе и семье.

\section{Литература}

1. Заславская Т.И. Современное российское общество: Социальный механизм трансформации. - М.: Дело, 2004. - С. 102-103.

2. Курбатов М.Г. Стихийное и сознательное в процессах социальной адаптации [Электронный ресурс]. — Режим доступа: 
http://www.archipelag.ru/text/155.htm (Дата обращения: 27.06.2019).

3. Латышева А.T. Российская социологическая мысль об адаптационных стратегиях населения: аналитический потенциал структурно-деятельностного подхода // Философия хозяйства. - М., 2006. - Ч. 1. C. $148-149$.

4. Мезенцева Е.Б. Профессиональная адаптация в условиях негосударственного сектора: анализ интервью с женщинамиспециалистами банковского бизнеса // В кн.: Мужчина и женщина в современном мире: меняющиеся роли и образы. - М., 1999. T. $1 .-$ C. 100.

5. Наумова Н. Ф. Жизненная стратегия человека в переходном возрасте // Социологический журнал. - 1995. - №2. - С. 5-22.

6. Розум С.И. Психология социализации и социальной адаптации человека. - M., 2006. - C. 304, 364.

7. Шабанова М. А. Социальная адаптация в контексте свободы // Социологические исследования. - 1995. — №9. - С. 81-84, 96.

\section{References}

1. Zaslavskaja T.I. Sovremennoe rossijskoe obshhestvo: Social'nyj mehanizm transformacii [Modern Russian society: Social mechanism of transformation]. - Moscow: Delo, 2004. Pp. 102-103.

2. Kurbatov M.G. Stihijnoe i soznatel'noe $\mathrm{v}$ processah social'noj adaptacii [Spontaneous and conscious in the processes of social adaptation] [Jelektronnyj resurs]. - URL: http://www. archipelag.ru/text/155.htm (Date accessed: 27.06.2019).

3. Latysheva A.T. Rossijskaja sociologicheskaja mysl' ob adaptacionnyh strategijah naselenija: analiticheskij potencial strukturnodejatel'nostnogo podhoda [Russian sociological thought about adaptation strategies of the population: analytical potential of the structural-activity approach] // Filosofija hozjajstva [Philosophy of Economy]. - Moscow, 2006. - Part 1. Pp. 148-149.

4. Mezenceva E.B. Professional'naja adaptacija $\mathrm{v}$ uslovijah negosudarstvennogo sektora: analiz interv'ju s zhenshhinami-specialistami bankovskogo biznesa [Professional adaptation in the conditions of the non-state sector: analysis of interviews with women-specialists of the banking business] // V kn.: Muzhchina i zhenshhina $v$ sovremennom mire: menjajushhiesja roli i obrazy [In the book: Man and woman in the modern world: changing roles and images]. Moscow, 1999. — Vol. 1. — P. 100.

5. Naumova N.F. Zhiznennaja strategija cheloveka $\mathrm{v}$ perehodnom vozraste [Life strategy human in the age of transition] // Sociologicheskij zhurnal [Sociological journal]. 1995. — №2. - Pp. 5-22.

6. Rozum S.I. Psihologija socializacii i social'noj adaptacii cheloveka [Psychology of socialization and sotsialnoy of human adaptation]. - Moscow, 2006. - Pp. 304, 364.

7. Shabanova M.A. Social'naja adaptacija v kontekste svobody [Social adaptation in the context of freedom] // Sociologicheskie issledovanija [Sociological studies]. — 1995. — №9. Pp. 81-84, 96. 


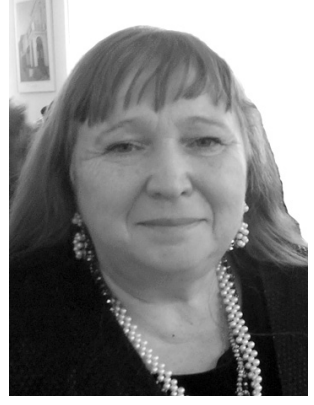

Николаева Людмила Сергеевна - доктор философских наук, профессор кафедры истории, философии и социальных технологий Новочеркасского инженерно-мелиоративного института имени А.К. Кортунова ФГБОУ ВО «ДГАУ».

Nikolaeva Lyudmila Sergeevna - Doctor of Philosophical Sciences, Professor of the Department of History, Philosophy and Social Technologies, Novocherkassk Reclamation Engineering Institute named after A. K. Kortunov (branch), Donskoy State Agrarian University.

346430, г. Новочеркасск, ул. Пушкинская, 111

111 Pushkinskaya st., 346409, Novocherkassk, Russia

E-mail: neverov72@mail.ru

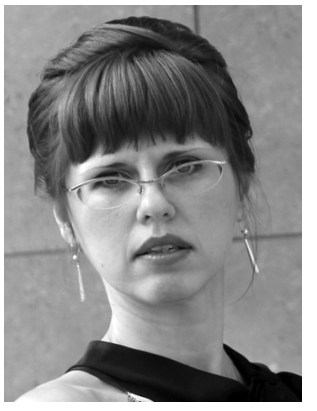

Загорская Ольга Вадимовна - кандидат социологических наук, доцент кафедры истории, философии и социальных технологий Новочеркасского инженерно-мелиоративного института имени А. К. Кортунова ФГБОУ ВО «ДГАУ».

Zagorskaya Olga Vadimovna - Candidate of Sociological Sciences, Associate Professor of the Department of History, Philosophy and Social Technologies, Novocherkassk Reclamation Engineering Institute named after A. K. Kortunov (branch), Donskoy State Agrarian University.

346430 , г. Новочеркасск, ул. Пушкинская, 111

111 Pushkinskaya st., 346409, Novocherkassk, Russia

E-mail: zagorskaya_nvch@mail.ru 